\title{
Stress Incontinence and Detrusor Instability/Urge Incontinence
}

\author{
E.J. McGuire and J.A. Savastano
}

\author{
Section of Urology, Department of Surgery, University of Michigan, Ann Arbor
}

\begin{abstract}
The overall incidence of detrusor instability in 603 women with stress incontinence was $30 \%$. One hundred seventy-two women had detrusor instability and/or urge incontinence preoperatively. Twenty-three additional women developed detrusor instability and/or urge incontinence only after operation. By eight weeks after operation $4 \%$ of the entire group or $14 \%$ of those who had detrusor instability or urge incontinence at any time pre- or postoperatively still had the difficulty with incontinence. These findings indicate that a small number of women with both stress incontinence and detrusor instabilty and/or urge incontinence will still have symptomatic urinary loss as a result of persistent detrusor abnormalities at eight weeks after operation.
\end{abstract}

Key words: detrusor, incontinence, stress

\section{INTRODUCTION}

A substantial number of women with stress incontinence will complain of urgency and urge incontinence, and some of these, on urodynamic evaluation, will demonstrate bladder contractions which are sudden and without warning and which the patient finds difficult or impossible to inhibit [Webster, 1983]. Whether these historical and urodynamic findings indicate that an operation is likely to fail to relieve incontinence is an unresolved question [Arnold et al, 1973].

Of 603 women with urodynamically and radiographically diagnosed stress incontinence, 180 had associated detrusor instability and/or stress urge incontinence. Five hundred eighty-two of these women have been followed for at least three years after operation to determine the outcome with respect to the relief of stress incontinence and detrusor abnormalities.

\section{METHODS AND PLAN OF STUDY}

The urodynamic methods have been described previously [McGuire et al, 1976] and consisted of the simultaneous measurement of bladder and urethral pressures in

Received for publication May 9th, 1985; accepted September 9th, 1985.

Address reprint requests to E.J. McGuire, Section of Urology, Department of Surgery, University of Michigan, 1405 E Ann Street, Ann Arbor, MI 48109. 
the upright position during bladder filling with $20 \%$ contrast material, at a rate of 60 $\mathrm{ml}$ per minute. The process was visualized fluoroscopically. Detrusor instability was diagnosed by a sudden increase in bladder pressure, and a change in urethral pressure and $x$-ray configuration of the urethra (most common was opening of the vesical outlet with closure of the midurethra, or a totally upen urethral sphincter mechanism). We also accepted a fall in midurethral closing pressure, with visible opening of the midurethra fluoroscopically, associated with intense urgency which was followed by contraction of the midurethra, but no change in bladder pressure as indicative of detrusor instability. Finally, we considered the bladder unstable if, on historical examination, the patient reported leakage at the sound of running water, or total bladder emptying precipitated by stress, even if the bladder was stable urodynamically. Of the 180 women with detrusor instability, 30 fell into the latter group.

Stress incontinence was defined as follows: Type I-fluoroscopically visible urinary leakage with coughing or straining associated with minimal urethral hypermobility but a resting proximal urethral closing pressure greater than $20 \mathrm{~cm}$ of water; type II-marked rotational descent of the urethra with coughing or straining, so that the internal meatus was at or below the level of the external meatus associated with fluoroscopically visible urinary loss but a normal proximal urethral closing pressure, (20 $\mathrm{cm} \mathrm{H}_{2} \mathrm{O}$ or greater); type III: incontinence associated with no, or very low, proximal urethral closing pressure, as well as incontinence following one or more retropubic operative procedures. Mobility of the urethra was unnecessary for the diagnosis of type III stress incontinence but did occur in some patients.

\section{SCHEDULE OF URODYNAMIC EVALUATION}

All patients were evaluated preoperatively, and postoperatively at one month, two months, six months, and at three years. Follow-up ranged from three to 12 years. After the third year, urodynamic studies were repeated only if incontinence persisted, or recurred.

\section{RESULTS}

Results of the initial evaluation are given in Table I. Twenty-seven percent had type I stress incontinence, $56.4 \%$ type II, and $16.2 \%$ type III. The overall incidence of detrusor instability was $30 \%$.

Of the 172 women with detrusor instability and/or urge incontinence preoperatively, 56 , or $31 \%$, continued to have urge incontinence at four weeks after operation.

TABLE I. Results of Initial Evaluation

\begin{tabular}{lcccr}
\hline Type SUI & No. & $\%$ & DI $^{\mathrm{a}}$ preoperative & $\%$ \\
\hline Type I & 165 & 27.4 & 32 & 19 \\
Type II & 340 & 56.4 & 124 & 36 \\
Type III & 98 & 16.2 & 24 & 25 \\
Total & 603 & 100 & 180 & 30 \\
\hline
\end{tabular}

${ }^{a} \mathrm{DI}=$ detrusor instability and/or urge incontinence. 
In contrast, of 410 women without detrusor instability and/or urge incontinence preoperatively, 24 , or $5.8 \%$, had incontinence at four weeks due to detrusor abnormalities. By eight weeks after operation, 25 patients, or $4 \%$ of the entire group and $14 \%$ of those with detrusor instability and/or urge incontinence at any time, were still troubled with incontinence due to that condition.

At six months, 23 of the 582 women continued to have incontinence associated with bladder instability and/or urge incontinence and at three years, 17 continued to manifest these symptoms.

\section{COMPARISON OF RESULTS BY TYPE OF OPERATION (TABLE II)}

Of 94 women treated by anterior repair, ten $(11 \%)$ had recurrent stress incontinence and two (2\%) had persistent detrusor instability and/or urge incontinence. Of 137 patients treated by a Marshall-Marchetti-Krantz procedure, one (.7\%) had recurrent stress incontinence and seven $(5.1 \%)$ had intractable detrusor problems. Of 170 who underwent a Burch procedure, one $(.6 \%)$ failed with recurrent stress incontinence, and six (3.5\%) failed as a result of bladder instability and/or urge incontinence. Of 143 patients who underwent a pubovaginal sling procedure four $(4.3 \%)$ had recurrent stress incontinence, while eight $(5.6 \%)$ had persistent bladder instability. No patient treated by needle suspension operation had incontinence at eight weeks after operation but the number of such patients is small. There were no significant differences in the rates of disappearance of persistence of detrusor instability following operation in any of these groups.

Of all women with symptoms of detrusor instability at any time pre- or postoperatively, $11 \%$ of those after anterior repair, $12 \%$ of those after a Marshall-MarchettiKrantz procedure, $12.5 \%$ of those after Burch, and $15 \%$ of those treated by a sling had persistent detrusor incontinence. None of these differences are significant. The de novo occurrence of detrusor instability and/or urge incontinence postoperatively ranged from $2 \%$ to $6 \%$, depending on operation. None of the operations had a significantly higher rate of occurrence of detrusor instability and/or urge incontinence as a new problem.

\section{DISCUSSION}

These results tend to substantiate both sides of a continuing argument. [It is clear that women with both stress incontinence and detrusor instability fare worse

TABLE II. Results of Surgery by Operation-Failure Rates for DI* and SUI at 6 Months

\begin{tabular}{lrrrrr}
\hline & No. & Failed DI & $\%$ & Failed SUI & $\%$ \\
\hline Anterior Repair & 94 & 2 & 2.2 & 10 & 11.0 \\
MMK & 137 & 7 & 5.1 & 1 & 0.7 \\
Burch & 170 & 6 & 3.5 & 1 & 0.6 \\
Sling & 143 & 8 & 5.6 & 4 & 2.8 \\
Stamey-Raz & 38 & 0 & & 18 & 5.2 \\
Total & 582 & 23 & 3.9 & 3.1 \\
\hline
\end{tabular}

$* \mathrm{DI}=$ detrusor instability and/or urge incontinence. 
after operation (with respect to total freedom from incontinence) than those with only stress incontinence.] However, neither group fared really badly, and $90 \%$ of the women with stress incontinence and detrusor instability and or urge incontinence were in fact totally relieved of urinary incontinence at six months, by operation alone. The differences in eventual outcome between patients with both conditions and patients with only stress incontinence are statistically significant. Patients treated by a retropubic procedure had a low rate of anatomic failure but the rate of persistent incontinence as a result of detrusor abnormalities was higher than after anterior repair. To some extent the better record of anterior repair with respect to detrusor problems was counterbalanced by a higher rate of failure due to recurrent stress incontinence. It may be that the obstructive character of a retropubic procedure encourages persistent detrusor instability since these operations also have a higher rate of de novo development of detrusor instability in the postoperative state. However, none of the differences in persistent detrusor instability were significant.

Patients with persistent detrusor instability had no distinguishing features on preoperative evaluation. Those with easily demonstrable detrusor instability did no better or worse than patients with detrusor instability diagnosed only by history. Detrusor instability does not seem to constitute a contraindication to stress incontinence surgery, but there are no distinguishing features in patients with both conditions which indicate that bladder instability is likely to disappear following operation. Emphasis on the preoperative diagnosis of detrusor instability urodynamically therefore seems to be somewhat misdirected. Even if one can document the presence of detrusor instability, that finding does not mean the patient will have a bad operative result. The primary diagnostic effort should probably be directed toward the clear identification of stress incontinence, and a secondary effort should be made to diagnose detrusor instability as an added risk factor, but not as a contraindication to surgery. If the diagnosis of stress incontinence is made, the eventual outcome of a surgical procedure with the respect to total freedom from incontinence is slightly worse in patients with both conditions than it is with patients with only stress incontinence, but the number of patients who fail solely as a result of detrusor instability is small.

This study suggests that in at least some patients, stress incontinence and detrusor instability are causally related. At present, there does not appear to be any good way to distinguish primary detrusor instability from that which is causally related to stress incontinence.

\section{REFERENCES}

Arnold EP, Webster JR, Loose H, Brown ADG, Turner-Warwick RT, Whiteside CG, Jequier AM (1973): Urodynamics of female incontinence: Factors influencing the results of surgery. Am J Obstet Gynecol 117:805.

McGuire EJ, Lytton B, Pepe V, Kohorn EI (1976): Stress urinary incontinence. Obstet Gynecol 47:255.

Webster GD (1983): The unstable bladder. In Raz S (ed): "Female Urology." Philadelphia: W.B. Saunders Company, pp 139-157. 